\title{
Research of the gender aspect of filmonym's translation
}

\section{S. A. Pankratova ${ }^{1}$}

${ }^{1}$ Saint-Petersburg State Institute of Film and Television, 13 Pravda Str., St. Petersburg 191119, Russian Federation

DOI: $10.18255 / 2412-6519-2020-3-300-307$

Research Article

Full text in Russian

The article deals with the translation of feminine film titles on the example of English filmonyms of the last decade. The article is aimed at the study of the filmonyms' translation in the Russian film discourse, which leaves its specific imprint on the translator's decisions. The paper treats the translation of feminine-marked filmonyms as a topical problem of the linguistics of gender and the theory of translation - the study of the means of translation of feature film titles from English to Russian from the point if view of gender-marked translators' slant. The application of the method of typological synchronous comparison allows to compare translation from the point of view of the feminine-masculine balance and the presence of feminine markers. The comparison is based on the thesis of adaptation and deformation of the source English film title. If the adaptation focuses on the convergence of the translation to the source culture and its specifics and is oriented on the mutrual cultural dialogue, then the deformation, on the contrary, prioritises the peculiarities of the accepting culture. The author of the article proves the thesis that in many cases the translation is not tolerant, the point of view of the translator affects the translation and therefore women are presented as nervous, obese, mentally different and emotionally unstable.

Keywords: filmonym; localization; gender; translation; transcreation; appropriation; domestication

\section{INFORMATION ABOUT THE AUTHORS}

$$
\begin{array}{l|l}
\text { Pankratova Svetlana A. } & \begin{array}{l}
\text { E-mail: svetpankrat@yandex.ru } \\
\text { Doc. Sc. (Philology) }
\end{array}
\end{array}
$$

For citation: Pankratova S. A. Research of the gender aspect of filmonym's translation // Social'nye i gumanitarnye znanija. 2020. Vol. 6, No 2. P. 300-307. (in Russ.) 


\title{
Исследование гендерного аспекта перевода фильмонимов
}

\author{
С. А. Панкратова ${ }^{1}$
}

${ }^{1}$ Санкт-Петербургский государственный институт кино и телевиденияул. Правды, 13, Санкт-Петербург, 191119, Российская Федерация

DOI: $10.18255 / 2412-6519-2020-3-300-307$

удК 81'373.612.2

Научная статья

Полный текст на русском языке

В работе рассматривается перевод феминно-маркированных фильмонимов на примере англоязычных киноназваний последней декады. Целью статьи является исследование перевода фильмонимов в российском кинодискурсе, накладывающем специфический отпечаток на переводческие решения. В фокусе внимания актуальная проблема гендерной лингвистики и теории перевода - изучение способов перевода названий художественных фильмов с английского языка на русский с позиций гендерно-маркированного отношения переводчиков к женщинам. Применение метода типологического синхронного сравнения позволяет сопоставить переводы на предмет баланса маскулинных и фемининных маркеров. Сравнение базируется на постулате об адаптации и деформации исходного англоязычного варианта киноназвания. Если адаптация фокусируется на приближении транслята к исходной культуре, ее специфике и ориентирована на взаимный диалог культур, то деформация, напротив, ставит в приоритет особенности принимающей стороны. Автор доказывает тезис о том, что во многих случаях такой перевод является нетолерантным и показывает женщин как людей с низким уровнем интеллекта и неконтролируемыми эмоциями. Тенденция к апроприирующему переводу с наложением позиции переводчика приводит к представлению женщин как существ нервных, тучных и неумных и неуравновешенных.

Ключевые слова: фильмоним; локализация; гендер; перевод; транскреация; апроприация; доместикация

\section{ИНФОРМАЦИЯ ОБ АВТОРАХ}

\begin{tabular}{l|l} 
Панкратова Светлана Анатольевна & $\begin{array}{l}\text { Email: svetpankrat@yandex.ru } \\
\text { Доктор филологических наук }\end{array}$
\end{tabular}

Для цитирования: Панкратова С. А. Исследование гендерного аспекта перевода фильмонимов // Социальные и гуманитарные знания. 2020. Том 6, № 3. С. 300-307.

(C) Панкратова С. А., 2020

Статья открытого доступа под лицензией СC BY-NC-ND (http://creativecommons.org/licenses/by-nc-nd/4.0/) 


\section{Введение}

Общепринятым является тот факт, что киноназвание - это визитная карточка фильма, именно оно впервые знакомит зрителя с фильмом, дает некое обобщенное представление о его содержании и определяет то место, которое кинокартина займет в прокате. Актуальность исследования гендерных фильмонимов несомненна потому, что броскость киноназваний с феминными лексическими единицами служит поводом к полемике касательно места и роли женщины в социуме как среди переводчиков, так и среди кинозрителей. Список переводов фильмонимов с дисбалансом гендерно-маркированных единиц постоянно пополняется, выступая в роли повода к размышлению о переводческой интерпретации. Теоретическая значимость исследования заключается в соотнесении классической теории перевода (Н. К. Гарбовский, В. В. Кабакчи, Т. А. Казакова, В. Н. Комиссаров, С. С. Толстой, С. В. Тюленев, А. В. Федоров, А. Д. Швейцер и др.) с ее современной интерпретацией, постулирующей, что перевод есть апроприирующий транскреативный процесс, предполагающий поиск оптимальных переводческих решений при условии соблюдения количественной и смысловой эквивалентности как критерия успешности интерпретации. Разнообразные сентенции касательно существования единственно верной переводческой стратегии носят двоякий, субъективный характер по причине того, что «... любая концепция (модель) перевода - это теория с человеческим лицом, продукт интерпретации фрагмента коммуникативной действительности, «вырезанного» из реальности сознанием исследователя» [1, с. 70].

Несмотря на широкую популярность кинематографа, каких-либо фундаментальных исследований в области фильмонимов практически не существует. И вместе с тем даже немногочисленные авторы, интересующиеся проблемой фильмонимов, делают довольно меткие наблюдения. Так, А. Н. Ткачева, исследовавшая французские фильмонимы, отмечает: «Содержательно и эмоционально адекватные эквиваленты в русском языке отсутствуют. К сожалению, уникальные смысловые компоненты, эффектность и выразительность французского заголовка при этом полностью и неизбежно утрачиваются» [2, с. 147].

Новизна исследования во многом связана с исследованием гендерного аспекта локализации фильмонимов и базируется на ряде научных исследовательских направлений.

В предлагаемой вниманию заинтересованных читателей статье фигурирует ряд специальных понятий, требующих расшифровки. Фильмонимы понимаются как названия кинофильмов, содержащие личные имена людей или животных, мест, организаций и т. п., которые пишутся с заглавной буквы и могут содержать 1-2, реже 3-5 лексических единиц. Под локализацией (от лат. 'locus' - место) понимается перевод и культурная адаптация наименования кинопродукта к особенностям определенной страны, региона или группы населения. Кинозаголовок в кинодискурсе является организующим элементом, он в сжатой форме передает основную идею содержания. Кинозаголовки могут быть однозначные, двузначные и многозначные, информативно насыщенные или «вапидные» (малоинформативные) [3]. Существует устойчивая взаимозависимость между кинозаголовком и кинопродуктом. «Взаимодействие двух кодов: словесного и кинесического 
рождает мощнейший убедительный эффект, влияющий на формирование яркого впечатления при восприятии кинопродукта, который накладывает отпечаток на сознании кинозрителя» [4, с. 357-359].

\section{Методы}

Метод типологического синхронного сравнения позволяет сопоставить исходник и перевод принимающей культуры на предмет баланса маскулинных и фемининных маркеров. Сравнение базируется на постулате об адаптации и деформации исходника. Если адаптация фокусируется на приближении транслята к исходной культуре, ее специфике и ориентирована на взаимный диалог культур, то деформация, напротив, ставит в приоритет особенности принимающей стороны [1, с. 69-78]. В статье также применяется метод функционального анализа фильмонимов, рассчитанный на то, чтобы оценить, в какой мере транслят отвечает нормам и лексическим стандартам принимающей культуры, степень «чуждости/приемлемости» итогового перевода в принимающей культуре.

Женское начало в языке рассматривается в теории гендера (0. Вейнингер, Дж. Хиггинс) и в отечественных исследованиях [5]. С женщинами, полагают авторы зарубежных исследований, ошибочно связывают особый, эмоциональный когнитивный стиль, сходный с мышлением людей креативных и непрофессионалов-любителей [6]. О. Вейнингер говорит о том, что женское мышление впечатлительно и носит «партикулярный» характер. Женщины, по его убеждению, мыслят «генидами»- рудиментарными, смешанными с чувствами единицами мысли, лишёнными логики. Мужчина всегда «зрит в корень» вещей, женщина «скользит по поверхности» [7]. Считают, что основанная на «маскулинной» (мужской) логичности картина мира прямолинейна, а женщина лишь косвенно своей впечатлительностью, созерцательностью, инстинктивностью выражает себя [8, с. 48]. Все это пережитки некорректного, маскулинного уклада.

\section{Результаты}

Углубление в тематику киноперевода не может обойти стороной само содержание фильмов, ту общую основу, на которой в идеальном мире должен опираться перевод. При анализе переводных названий мы обратимся к содержанию фильма, укажем его содержательные атрибуты. На примере уже упомянутого выше фильма поясним, что содержательные атрибуты фильма в том виде, в каком они представлены в кинопрограммах, содержат самую лишь общую информацию. Это, прежде всего, собственно название фильма «Бегущий по лезвию», его перевод Blade Runner, год выхода - 1982, жанр - фантастический триллер, постановщик Ридли Скотт, первые исполнители - Гаррисон Форд, Рутгер Хауэр, Шон Янг, и то, что в кинематографии принято называть «логлайн» (от англ.: logline - основная фабула), история, изложенная в одном развернутом предложении объемом максимум 15-20 слов. По роману Филлипа К. Дика. Бывший полицейский космического патруля должен выследить и уничтожить вышедших из-под контроля андроидов.

Рассмотрим ряд фильмонимов с привлечением героев-мужчин и проанализируем, насколько полно содержание фильма отражено в его заголовке. Нами 
было обнаружено несколько фильмонимов с героями-мужчинами. Приводим список и краткое обсуждение:

1. «Вышибалы» (DodgeBall: A True Underdog Story) (2004) комедия.

2. «Герой-одиночка» (Last Man Standing) (1996) спортивная драма.

3. «Герой супермаркета» (Mall Cop) (2009) комедия.

4. «Мальчишник в Beгасе» (Hangover) (2009) эксцентрическая комедия.

5. «Образцовый самец» (Zoolander) (2001) эксцентрическая комедия.

6. «Солдаты неудачи» (Tropic Thunder) (2008) пародийная комедия.

7. «Хеллбой: Герой из пекла» (Hellboy) (2004) ужасы/фантастика.

Комедия 2004 года «Вышибалы» (DodgeBall: A True Underdog Story) (2004) peжиссера Роусона Маршалла Тёрбера с Винсом Воном и Кристин Тейлор в главных ролях рассказывает о владельце крупной сети фитнесс-центров. Содержание лишь частично отражено в названии, ибо детская игра в вышибалы, в которой дети, находясь напротив друг друга, бросают мяч, чтобы выбить противника из круга, представляет завязку, исходный момент фильма. Мужские провалы в переводе киноназваний замалчиваются, как это имеет место в названии «Вышибалы» (DodgeBall: A True Underdog Story). Понятие «неудачник» (underdog) исключается из фильмонима, имеет место деформирующий перевод с компенсацией исходника. На первый план выносится положительная сторона персонажа. «Герой-одиночка» (Last Man Standing), «Герой супермаркета» (Mall Cop), «Образцовый самец» (Zoolander). Очевидно, что мужской образ в переводе фильмонимов поддерживает стереотип о мужском превосходстве.

\section{Обсуждение}

Обращаясь к переводу феминных фильмонимов, отметим, что материалом для исследования послужили более десятка обнаруженных в современных источниках (биллборды, сайты и пресса) киноназваний [9]:

1. «Дочь и мать ее» (Captured) (2017) комедия.

2. "Дикая штучка» (Wild Target) (2009) комедия.

3. «Замерзшая из Майами» (New In Town) (2008) ромком.

4. «Заложница» (Taken) (2008) криминальный боевик.

5. «Зараженная» (Maggie) (2015) хоррор.

6. «Конченая» (Terminal) (2018) триллер.

7. «Красотки в бегах» (Hot Pursuit) (2015) криминальная комедия.

8. «Красотка на всю голову» (I Feel Pretty) (2018) комедия.

9. «Красавища для чудовища» (Mary Shelley) (2017) драма.

10. «Моя ужасная няня» (Nanny McPhee) (2005) фильм-сказка.

11. «Невеста с того света» (Over Her Dead Body) (2008) комедия.

12. «Несносные леди» (Mother's Day) (2016) драма.

13. «Oтпетые мошеннищы» (The Hustle) (2019) комедия.

14. «Очень опасная штучка» (One For The Money) (2012) экшн-комедия.

15. «Очень плохие девчонки» (Rough Night) (2017) комедийный триллер.

16. «Поймай толстуху, если сможешь» (Identity Thief) (2013) комедия.

17. «Проклятие моей матери» (The Guilt Trip) (2012) ромком.

18. «Проклятие монахини» (The Nun) (2018) мистика. 
В этой категории представлено 18 киноназваний с женщинами в заглавных ролях. Судя по переводу, женщин подразделяют на несколько категорий:

- неудачницы: «Замерзшая из Майами» (New In Town);

- неумные: «Красотка на всю голову» (I Feel Pretty);

- жертвы: «Красавица для чудовища» (Mary Shelley);

- преступницы: «Красотки в бегах» (Hot Pursuit);

- стервозные: «Конченая» (Terminal);

- тучные: «Поймай толстуху, если сможешь» (Identity Thief).

Проанализируем степень учета содержательной стороны фильмов в переводе киноназваний. Так, в первой из выделенных нами категорий (неудачницы) актриса Рене Зеллвегер в фильме «Замерзшая из Майами» (New In Town) играет карьеристку Люси Хилл, которая прибывает из солнечного Майами в снежную Миннесоту в рабочую командировку. Явное акцентирование женских неудач в переводе фильмонима никак не оправдано, девушке оказывают всяческую поддержку обитатели снежного штата Миннесота.

Итак, налицо явный сексистский уклон киноназваний. Вышедший в 2002 году Словарь гендерных терминов так трактует явление сексизма: «... гендерная асимметрия, воспроизводящая ущербность образа женщин в картине мира» [10, с. 232]. Гендерные стереотипы тесно связаны с культурным типом наций. В культурологии даже существует деление на маскулинные (Австрия, США, Великобритания) и феминные (скандинавские страны, Чили, Таиланд) культуры (концепция Г. Хофстеде). В маскулинном обществе гендер важен, а от мужчины требуют быть «стойким оловянным солдатиком», иначе вы - «лузер», т. е. неудачник. В феминном обществе важны социальные роли, но не пол, все имеют право на слабость, приветствуется скромность и консенсус, превалирует стремление к улучшению качества жизни и взаимная забота.

Киноназвания с невыгодным образом женщин работают на усиление стереотипа о женщинах как эмоциональных, нестабильных созданиях. Во многом этот стереотип есть производная общественного нежелания по достоинству воспринимать женщин, отводить им равное место в общественной иерархии, результат зависти. Р. Лакофф отметил, что женщины как социальный субъект вынуждены проводить жизнь в ситуации так называемой «двойной связанности» (от англ.: double bind - двойной переплет). Данная ситуация предполагает, что женщины, успешно сигнализирующие о своем авторитете и высоком социальном статусе, становятся мишенью общественного осуждения по причине несовпадения общественных представлений и их фактической жизненной позиции по вопросам женственности и ее роли в обществе. В то же время женщины, демонстрирующие более феминные модели поведения, могут вызвать осуждение как неспособные к социальному и личностному росту.

Много сказано о роли личных местоимений и наименованиях профессий, ограничивающих гендерное равноправие. Это касается явных языковых проявлений сексизма. Теперь проблема состоит не в том, чтобы обнаружить в тексте сексистский подтекст, а в том, чтобы объяснить, каким именно образом этот подтекст манипулирует читателем, и показать, как подобный текст сконструирован. На современном этапе сексизм процветает на уровне предположений, недомолвок, иронии и юмора [11]. Как отмечает А. А. Григорян, это есть скрытый, но не менее обидный «неявный сексизм» [12, с. 231-236]. Так, выражение 'top totty' 
(классная телка), используемое в телепрограмме, как бы предполагает юмор и иронию, его сложнее оспорить. Юмор служит маскировкой сексизма и ширмой, помогающей отрицать наличие сексизма [13, с. 231-234]. Это происходит «на правах сильного», как полагает Н. Е. Камовникова [14, с. 154-157]. Во многих источниках сообщения о женщинах в общественной сфере подрывают образ компетентных, способных и знающих работниц, общественная деятельность которых подается как исключительная, как небывалый успех [15; 16]. Как нам представляется, преувеличенное подчеркивание качеств, присущих тому или иному полу, негативно сказывается на общественном раскладе сил, вызывая чувство солидарности у одной гендерной группы против другой.

\section{Выводы}

Подводя итог, хотелось бы отметить, что популярное за рубежом направление политической корректности поощряет уважительное отношение ко всем социальным слоям и группам, а языковая политика корректности предписывает избегать в речи слов и выражений, ведущих к дискриминации личности по расовому, этническому, религиозному, половому, социальному статусу, внешнему виду, возрасту и состоянию здоровья. Результаты проведенного в статье исследования гендерного аспекта фильмонимов показали, что политическая корректность пока не стала в нашей стране всеобъемлющей идеологией, идеологией, влияющей на образ мыслей и манеру речи массового зрителя. Как показал анализ, при переводе фильмонимов с феминным гендерным компонентом происходит неравнозначная, деформирующая исходник трансформация, а мировоззренческая позиция переводчика накладывает свой отпечаток на переводимый материал. Рекомендацией может стать характеризация мужчин и женщин в единой системе координат, выравнивание гендерных статусов.

\section{Ссылки / References}

1. Леонтьева К. И. Дискурсивная онтология, субъективный принцип, перспективизация: интегративный анализ переводческой деятельности с антропоцентрических социокогнитивных позиций // Вопросы когнитивной лингвистики. 2017. № 4. С. 69-78.

2. Ткачева А. Н. Особенности российской локализации французских кинозаголовков // Филологические науки. Вопросы теории и практики. 2019. Том 12. Выпуск 2. C. $144-148$.

3. Швейцер А. Д. Теория перевода: Статус, проблемы, аспекты. М.: Наука, 1988. 215 с.

4. Петухова Т. И. Языковая актуализация концептуальных пространств как фактор формирования ценностного аспекта кинотекста // Когнитивные исследования языка. 2016. № 26. С. 357-359.

5. Киселева С. В. Сущность многозначного слова в английском языке. СПб.: Астерион, 2009. 216 c.

6. Дэвидсон Д. Что означают метафоры // Теория метафоры. М., 1990. С. 173-194.

7. Вейнингер 0. Пол и характер М.: Терра, 1992. 480 с. 
8. Х Хиггинс Р. Седьмой враг; Человеческий фактор в глобальном кризисе // Глобальные проблемы и общечеловеческие ценности. М.: Прогресс, 1990. С. 34-55.

9. Петербургский телезритель. 2018. № 36 (1107).

10. Словарь гендерных терминов. М.: Информация XXI век, 2002. 256 с.

11. Hardman M. J. The Sexist Circuit of English // The Humanist. 1996. March-April. Vol. 56. № 2. P. 25-32.

12. Григорян А. А. Неявный сексизм: об одном из способов его проявления в современной англоязычной литературе // Англистика XXI века: Материалы IX Всероссийской межвузовской научно-методической конференции. СПб., 2019. C. 231-236.

13. James D., Clark S. Women, men and interruptions // Gender and Conversational Interaction. New York: Oxford University Press, 1993. P. 231-280.

14. Камовникова Н. Е. На правах сильного: художественный перевод в контексте языковой политики // Перевод. Язык. Культура. Сборник трудов VII международной научно-практической конференции. СПб: Ленинградский государственный университет им. А. С. Пушкина, 2016. С. 154-157.

15. Herbert R. K. Sex-based differences in compliment behavior // Journal of Pragmatics. 14. 1990. № 2. P. 193-218.

16. Holmes J. Women, Men and Politeness. London: Longman, 1995. 254 p. 